\title{
Relationship between gender and subjective well-being: survey of married couples
}

\author{
Natalia Yu. Buhner ${ }^{1 *}$, Irina $V$. Rogozina ${ }^{1}$, Natalia $V$. Tsyganenko ${ }^{1}$, Olga $V$. Tiskova ${ }^{1}$, Natalia N. Bespalova ${ }^{2}$ \\ ${ }^{1}$ Polzunov Altai State Technical University, 46 Lenina St., Barnaul, Russia \\ ${ }^{2}$ Altai State Institute of Culture, 66 Lenina St., Barnaul, Russia
}

\begin{abstract}
Subjective well-being refers to people's experience and self-reported measures about the quality of their lives, cognitive evaluation of social and economic activities. This evaluation depends on different factors, like income, standards of living, mood, adaptability, expectation on job-to-pay ratio. The importance of gender in this process cannot be underestimated. Based on data obtained by a sociological survey we examined 75 Altai Krai's married couples responses to determine gender differences in subjective well-being, using a multi-step procedure involving methods of frequency and correlation analysis, the method of studying the relationship between categorical variables. Our results reveal several gender differences, which greatly appear in expectations on a job-to-pay ratio.
\end{abstract}

\section{Introduction}

Significant transformation in the social, economic, political spheres of society has been made in Russia over the last past forty years. Such changes made a graduated regional effect on well-being of the Russian people. Thus, according to statistics, Altai Krai citizens' income is in the 70th place (among 85 possible) in 2021 [1]. This means that in this region in 2020 :

- ratio of median income to the cost of a fixed set of goods and services was 1.22;

- proportion of the population below the poverty line (income less than 1 minimum wage) was $17.5 \%$;

- share of the population living in the extreme poverty line in 2020 (income less than 0.5 minimum wages) was $2.4 \%$.

Even a cursory glance at these data suggests the plight of the region's population. In this regard, the issue of subjective economic and social well-being in different Russian regions acquires special relevance. As noted by several scientists (R. Ingelhart, K. Wellsell, M. Argyle), subjective well-being does not directly depend on the population's income [2, 17]. Among the scientists engaged in the study of well-being, there are $\mathrm{N}$. Bradburn [3], E. Diener [4], K. Riff [5]. The study of subjective well-being as an alternative to the traditional approach measuring economic and social achievements occupies a special place in the Commission on the Measurement of Economic Performance and Social Progress report in 2009 (by J. Stiglitz, A. Sen, J.P. Fitoussi) [6].

Psychologists and social psychologists have traditionally treated various aspects of well-being, utilized to describe healthy individuals (E.E. Bocharova [7]; A.I. DontsovA, E.B. Perelygina, A.M. Rigel [8]; L.V. Karapetyan [9]). Furthermore, V.A. Khashchenko develops the concept of subjective economic well-being, which he understands as "a basic construct of economic consciousness, which expresses a person's attitude to his/her actual and future material well-being [10]. Economists are also interested in the issue and talk about measuring of well-being in their member country (T.O. Archakova, E.Sh. Garifulina [11]. A.V. Vinokurova, E.Yu. Kostina [12]; M.K. Gorshkov, V.V. Petukhov, A.L. Andreev et al. [13]; L.S. Kiseleva [14]). Gender aspects of well-being have been studied in the works of A.V. Shperlin [15]; A.I. Antonov, V.M. Karpova, S.V. Lyalikova [16]; M. Pinkwart, S. Sorensen [17]; E. Diener, K. Lee, M. Zuckerman [18]; E. Osin, D. Leontiev [19]. Thus, M. Pinkwart, S. Sorensen note that men are more satisfied with their lives than women were [17]. E. Osin and D. Leontiev record a weak positive relationship (using Spearman's coefficient, further denoted $p$ ) between gender and happiness $(\mathrm{p}=0.14)$, gender and life satisfaction $(\mathrm{p}=0.09)$, gender and negative affect $(\mathrm{p}=0.10)$, gender and emotional wellbeing $(p=0.10)$, gender and mental well-being $(p=$ 0.08) [10].

However, there is no unified methodological approach in modern sociological science that can combine objective parameters of well-being, like income, employment, etc., with measurement of subjective well-being, which is reflected in individual life satisfaction.

Attempts to define the concepts of social well-being and economic well-being have been made by various researchers. The concept of "good" is the key to the analysis of this phenomenon, the philosophical interpretation of which we find in the works of Aristotle, J.-J. Rousseau, L.N. Tolstoy. Passing through the stages of transformation, philosophy began gradually penetrate the sphere of social policy, and the concept of "wellbeing" became one of the key standards in "welfare states" construction. As a consequence, it became very

* Corresponding author: nbuhner@mail.ru

(C) The Authors, published by EDP Sciences. This is an open access article distributed under the terms of the Creative Commons Attribution 
important to find empirical methods for conducting wellbeing research in different countries. The earliest works in this field belonged to E. Diener (1984), who proposed a scale of "life satisfaction" and a tripartite model of subjective well-being. Modern researchers of well-being noted the presence of both objective and subjective meanings in this concept, but the subjective side (Subjective Well-Being) of being was the most productive for scientists. The current philosophical approach was considering well-being in three main perspectives: hedonic (emphasizing the emotional and cognitive-evaluation component), eudemonic (focusing on the indicator of positive personal functioning), and mixed, demonstrating a close relationship between hedonia and eudemonia.

\section{Problem Statement}

The study of well-being is especially productive through the gender approach in the context of ongoing socioeconomic transformations in Russia, which are perceived among spouses depending on the gender.

Gender peculiarities of subjective well-being are related to 1) cognitive differences between the genders; 2) differences in the involvement of husband and wife in economic activity; 3) differences in the involvement of husband and wife in social activity.

\section{Research Questions}

The object of the study is married couples living in the Altai Krai. The subject of the study is gender differences in subjective social and economic well-being.

Subjective economic well-being depends on the family's income and standards of living. Subjective social well-being depends on the mood, the individual's adaptability, expectations regarding the job-to-pay ratio.

Therefore, in our study, we are going to evaluate the relationship between gender and subjective well-being, as well as to highlight gender differences in subjective well-being.

\section{Purpose of the Study}

The purpose of the study is to measure and to analyze subjective social and economic well-being. The hypothesis of the study is that there are general and specific well-being features, determined by gender.

The term well-being has different interpretations; N.V. Goffe and G.A. Monusova suggest using the concepts of "well-being", "social well-being" and "socioeconomic well-being" as synonyms [6, p. 22]. From the sociological perspective, well-being is seen as "the availability of resources that allow a person, a group, a society to feel confident in the present day and the potential to maintain a stable state in the near and distant future" [9, p. 10].

In our research paper, social well-being is understood as a positive assessment by a person to meet social, including psychological needs in their everyday life. Economic well-being is understood as a positive assessment by a person of his/her financial security, satisfying material needs.

\section{Research Methods}

Parents of I.I Polzunov Altai State Technical University students aged from 38-63 (from 38 to 51 years old for women and from 40 to 63 years old for men) took part in the study. At the stage of a preliminary survey, the respondents were interviewed by the questionnaire, which consisted of 6 questions:

- "What is your gender?" (binary scale: 1. Male, 2. Female);

- "Which of the following definitions is the most appropriate for assessing your living conditions?" (4point scale: 1 . I have everything I need for life, 2. I have almost everything I need, 3. I have some of the necessary, 4. I have almost nothing);

- "How would you rate the level of your adaptation to the changes taking place in the country?" (4-point scale: 1. Easily adapted/opened to new opportunities; 2. Adapted; 3. Adapting with difficulty/living as before; 4 . I can't adapt to the changes);

- "What mood do you have most often?' (5-point scale: 1. Beautiful; 2. Normal; 3. Tense; 4. Anxious; 5. Other);

- "What would you prefer if you could choose ...?" (5-point scale: 1. Free schedule, salary does not really matter; 2. Full-time, fixed salary; 3. Irregular working hours, high wages; 4. Own business; 5 . Hard to answer):

- "How would you rate your income level?" (4-point scale: 1 . High; 2 . Above average; 3 . Medium; 4. Low).

The processing was carried out using the methods of mathematical statistics of the IBM SPSS Statistics 17.0 program.

In the next stage of the study, the data were processed using the methods of frequency and correlation analysis, the method of studying the relationship between categorical variables.

\section{Findings}

The performed correlation analysis made it possible to determine the strength of the relationship between gender and some indicators of social and economic wellbeing, such as living conditions; mood; income; adaptability; priorities regarding the job-to-pay ratio.

Among these five variables, the strongest relationship was found between two sets of data: gender and the priorities regarding the job-to-pay ratio. The Spearman correlation coefficient of it took value $p=-0.271$. Over correlation, coefficients were ranging from 0.125 to 0.011 (Table 1).

Table 1. Correlation (by Spearman)

\begin{tabular}{|c|c|}
\hline \multirow{2}{*}{ Scales } & Correlations \\
\cline { 2 - 2 } & Gender \\
\hline JOB-TO-PAY RATIO & -0.271 \\
\hline ADAPTABILITY & 0.125 \\
\hline INCOME & 0.111 \\
\hline LIVING CONDITIONS & -0.099 \\
\hline MOOD & -0.011 \\
\hline
\end{tabular}


The survey revealed women are more able to assess their priorities regarding work and wages. Most men and women chose "Full-time, fixed salary" (36.4\% and $62.5 \%$ respectively). They perceive work as a guaranteed job and salary. Interestingly, men would like to have more free time (they choose the answer "Free schedule, salary does not matter much" - $9 \%$ - men, $2.5 \%$ women), and women would like to earn more (the answer choice "Irregular working hours, high salary" $18.2 \%$ - men, $25 \%$ - women). Only $9.1 \%$ of men and $7.5 \%$ of women would like to have their own business. $2.5 \%$ of women and $27.3 \%$ of men found it difficult to answer the question "What are your priorities regarding work and wages?" (Figure 1)

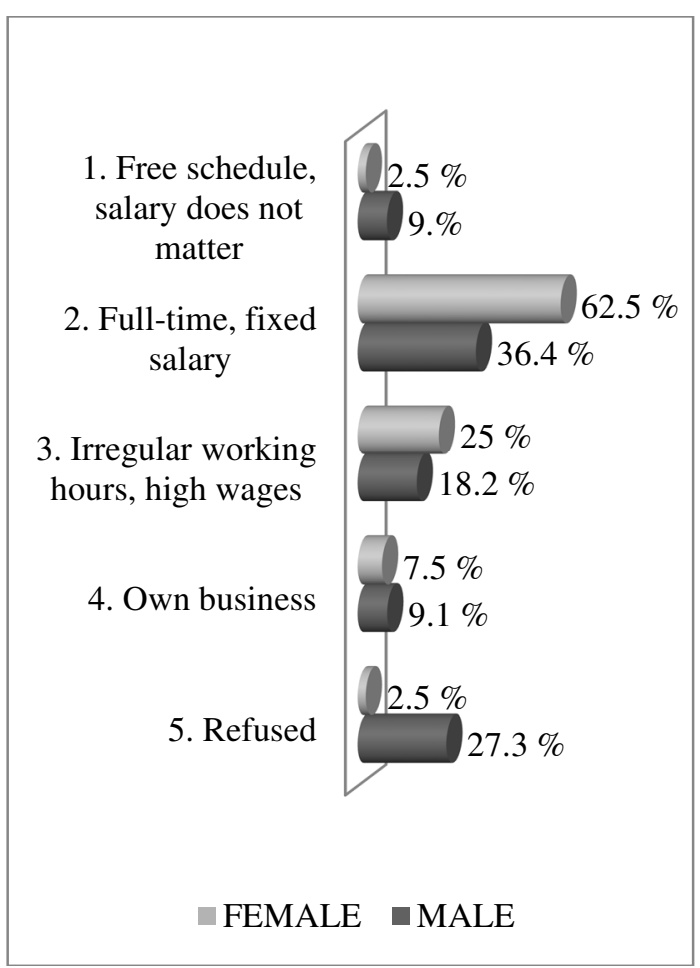

Fig.1. Relationship between gender and priorities regarding the job-to-pay ratio

We can note women's potential as agents for adaptation is greater than that of men. Conducting study claims that about $45 \%$ of females and only $27.3 \%$ among men are adapted to changing social conditions (we summed two answers "Easy adapted/opened up new opportunities" or "Adapted" to the question "How would you assess the level of your adaptation to the changes taking place in the country?"). Thus, the number of adapted women is twice as high as the number of men. Most of the respondents adapt to difficulty or live as they used to live - $69.7 \%$ among male respondents and $50 \%$ of female respondents, respectively. $3 \%$ of men and $5 \%$ of women cannot adapt yet (Table 2).

Table 2. Relationship between gender and adaptability

\begin{tabular}{|c|c|c|}
\hline VARIABLES & MALE & FEMALE \\
\hline $\begin{array}{c}\text { 1. Easily adapted/opened } \\
\text { to new opportunities }\end{array}$ & $2 \%$ & $7.5 \%$ \\
\hline
\end{tabular}

\begin{tabular}{|c|c|c|}
\hline 2. Adapted & $25.3 \%$ & $37.5 \%$ \\
\hline $\begin{array}{c}\text { 3. Adapting with } \\
\text { difficulty/living as I used } \\
\text { to live }\end{array}$ & $69.7 \%$ & $50.0 \%$ \\
\hline $\begin{array}{c}\text { 4. I can't adapt to } \\
\text { changes }\end{array}$ & $3.0 \%$ & $5.0 \%$ \\
\hline
\end{tabular}

The results of the study revealed slight gender differences in the assessment of living conditions, by analyzing the answers to the question "Which of the following definitions is the most appropriate to assess your living conditions?" Here we can see slight differences in extreme assessments of men and women. In general, higher positive assessments were received from the female half of respondents. Thus, $63.7 \%$ of men and $77.5 \%$ of women said that they have everything or almost everything they need (answer options "I have everything I need in my life" and "I have almost everything I need"). Men slightly more often pointed to the average level of living conditions (answer "I have almost everything I need") and below average level of living conditions (answer "I have some of the things I need"), and women to the high and average levels of living conditions. Besides, the fact that the women are more inclined to extreme assessments: have everything or have almost nothing. It is women who dominate the choice of extreme responses (Figure 2).

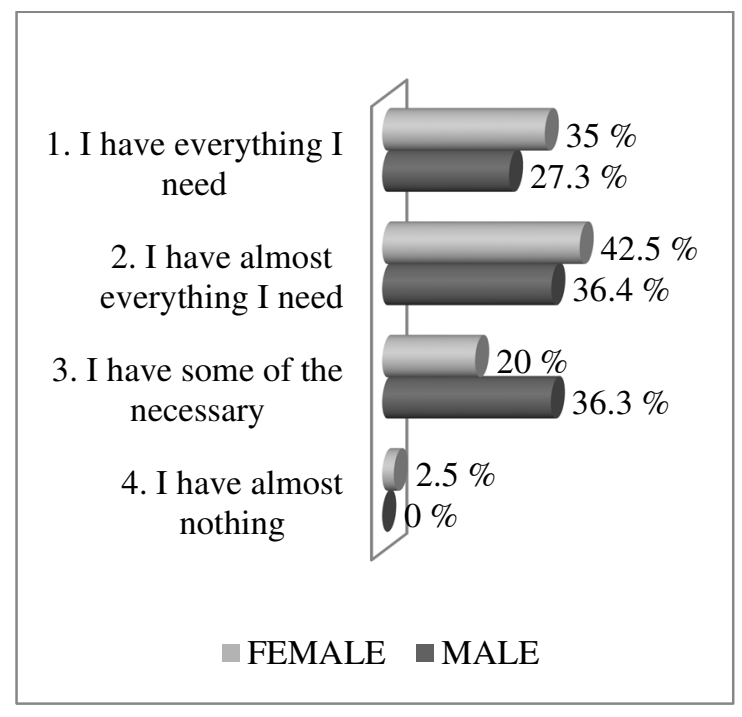

Fig. 2. Relationship between gender and living conditions

A roughly similar picture is observed when respondents assessing income in response to the question "How would you rate your income level?". Interestingly, respondents rate their living conditions higher than their income. Thus, the majority of respondents $(55.5 \%$ among men and $50 \%$ among women) assessed income as medium. 41.5 percent among men and 44.4 percent among women have above average income. Some men and women who reported that have more than average living conditions may also have an average income. The percentages of men and women who said that they have high income are roughly equal at 3 percent. This represents 3 percent of men and 3.7 percent of women (Figure 3 ). 


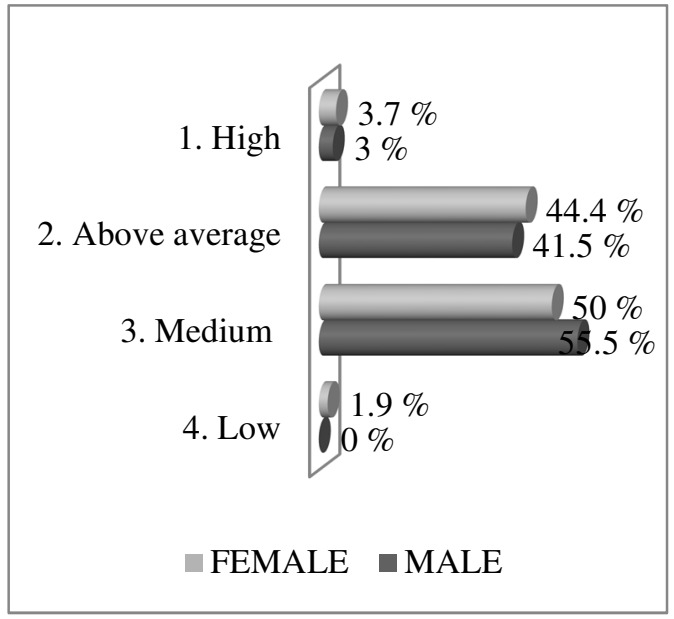

Fig. 3. Relationship between gender and income

Correlation analysis did not reveal any significant coefficient between mood and gender. Most of the respondents $(85.9 \%$ among men and $70 \%$ among women) assessed their mood as "Normal". "Excellent" is noted by $0 \%$ of men and $10 \%$ of women, "Tense" - 3.3\% and 7.5\%; "Anxious" - $1.7 \%$ and 10\%; "Other" - 9.1\% and $2.5 \%$, respectively (Table 3 ).

Table 3. Relationship between gender and mood

\begin{tabular}{|c|c|c|}
\hline VARIABLES & MALE & FEMALE \\
\hline 1. Beautiful & $0.0 \%$ & $10.0 \%$ \\
\hline 2. Normal & $85.9 \%$ & $70.0 \%$ \\
\hline 3. Tense & $3.3 \%$ & $7.5 \%$ \\
\hline 4. Anxious & $1.7 \%$ & $10.0 \%$ \\
\hline 5. Other & $9.1 \%$ & $2.5 \%$ \\
\hline
\end{tabular}

\section{Conclusion}

Conducting subjective well-being in different regions of a country is very important for several reasons. First of all, it helps to measure the relationship between objective indicators of regional development, such as average wages, and subjective indicators of subjective well-being, such as mood. Second, the study of the subjective well-being within the couple is necessary, since the family is the basis of modern society.

Thus, as a result of the study, it was revealed that social and economic well-being has its own gender specificity. To the greatest extent, gender differences manifest themselves in the evaluation of the job-to-pay ratio, as well as in the potential for adaptability.

\section{References}

1. Rating of regions by the income of the population. RIA Rating. Access mode: https://riarating.ru/infografika/20210706/630203876.htm 1

2. M. Argyle The Psychology of Happiness. (2003)

3. N.M. Bradburn The Structure of Psychological WellBeing. (1969)
4. E.Diener Subjective Well-Being. Psychological Bulletin. Vol. 95 (3). P. 542-575. (1984)

5. C.D. Ryff Happiness is Everything, or Is It? Explorations on the Meaning of Psychological WellBeing. Journal of Personality and Social Psychology. Vol. 57. P. 1069-1081. (1989)

6. J. Stiglitz, A. Sen, J.P. Fitoussi Mismeasuring our lives: Why GDP Doesn't add up. (2010)

7. E.E. Bocharova The relationship between subjective well-being and the social activity of the individual: a cross-cultural aspect. Social Psychology and Society.V. 3. No. 4. P. 53-63. (2012)

8. A.I. Dontsov, E.B. Perelygina A.B., A.M. Rigel Objective and subjective well-being: two approaches to the topic under study. Voprosy psychologii. Vol.5.P. 314. (2016)

9. L.V. Karapetyan. Theoretical approaches to the understanding of subjective well-being. Izvestia Uralskogo Federalnogo Universita. Ser. 1. Problems of Education, Science, and Culture. Vol. 1 (123).P. 171182. (2014)

10. V.A. Khashchenko Psychology of Economic WellBeing.(2012)

11. T.O. Archakova, E.Sh. Garifulina Measuring subjective well-being of children in Russia: from local social practices to a federal strategy. Public Opinion Monitoring: Economic and Social Changes. Vol. 1. P. 276-295. (2020)

12. A.V. Vinokurova, E.Yu. Kostina Social well-being of the population in the context of regional development (by the example of Primorsky Krai). Bulletin of Buryat State University. Vol. 6. P. 49-53. (2015).

13. N.V. Goffe, G.A. Monusova Social Well-Being: Perception of Realities. Yuzhno-Russian Journal of Social Sciences. Vol. 3. P. 21-36. (2018)

14. L.S. Kiseleva Welfare of the Russian Population: Architectonics, Subjective Perception and Regional Uniqueness. (2020)

15. A.V. Shperlin The significance of gender differences and family status in the determination of subjective economic well-being. Bulletin of the TSTU - Vol. 142.P. 66-72. (2014)

16. A.I. Antonov, V.M. Karpova, S.V. Lyalikova Ratio of Desired and Actual Welfare of Families: According to the Sociological and Demographic Survey of Married Couples. Living Standards in Russian Regions. Vol. 17. P. 121-131. (2021)

17. M. Pinquart, S. Sörensen Gender differences in selfconcept and psychological well-being in old age: A meta-analysis. The Journals of Gerontology, Series B: Psychological Sciences and Social Sciences. Vol. 56. P. 195-213. (2001)

18. M. Zuckerman, C. Li, E. F. Diener, Societal conditions and the gender difference in well-being: Testing a three-stage model. Personality and Social Psychology Bulletin. Vol. 43. P. 329-336. (2017) 19. E.N. Osin, D.A. Leontiev Short Russian-language diagnostic scales of subjective well-being: psychometric characteristics and comparative analysis. Public Opinion Monitoring: Economic and Social Changes. Vol. No. 1. P. 117-142. (2020) 